\title{
LA INTERVENCIÓN DE RIDRUEJO E IBÁÑEZ MARTÍN EN LA VIDA DEL POETA MIGUEL HERNÁNDEZ
}

\author{
JuSTO FORMENTíN IBÁÑEZ Y JOSÉ ANDRÉS-GALLEGO ${ }^{1}$ \\ Centro de Humanidades, CSIC, Madrid
}

Es difícil decir algo más sobre la etapa final de la vida de Miguel Hernández. Como es sabido, el poeta - hombre de extracción social humilde, aunque no exactamente pobre, y de formación cristiana- había ido evolucionando hacia posiciones de izquierda al entrar en contacto con otros poetas y escritores de Madrid, desde 1931. "Transformación terrible y cruel - -exclamará su amigo Ramón Sijé en una carta que le escribe en 1935-. [...] Nerudismo (iqué horroroso!, Pablo y selva, ritual narcisista e infrahumano de entrepiernas, de vello de partes prohibidas y de prohibidos cabellos); aleixandrismo; albertismo» ${ }^{2}$.

Durante la Guerra, militó en las filas del Ejército de la República. Militó, ¿de qué manera? En la bibliografía existente se concreta poco; se dice que, el 15 de mayo de 1932, había sido detenido por primera vez, concretamente en Alcázar de San Juan, cuando volvía de Madrid a Orihuela. Y de nuevo el 6 de enero de 1936 en San Fernando de Jarama, en esta ocasión hasta el punto de que un grupo de escritores y artistas firmó un manifiesto en su favor y de denuncia del trato inhumano y brutal que el poeta había recibido de la Guardia Civil. Entre los firmantes estaban (y

\footnotetext{
1 Justo Formentín Ibáñez es el principal responsable de la investigación que da lugar a estas páginas; José Andrés-Gallego lo es de la elaboración de las conclusiones. Se inscribe, por otra parte, este estudio en el proyecto de investigación Política cultural del primer franquismo desarrollado bajo los auspicios de la Dirección General de Investigación, Ministerio de Ciencia y Tecnología (BHA 2003-09878-C02).

${ }^{2}$ Apud Manuel MuÑoz Hidalgo, Cómo fue Miguel Hernández, $5^{\mathrm{a}}$ ed., Barcelona, Editorial Planeta, 1978, p. 121. Las noticias que recogemos sobre la vida y el proceso del poeta, si no decimos lo contrario, proceden de SÁNCHEZ VIDAL, Miguel Hernández, desamordazado y regresado, Barcelona, Editorial Planeta, 1992, passim; José Luis FERRIS, Miguel Hernández: Pasiones, cárcel y muerte de un poeta, Madrid, Ediciones Temas de hoy, 2002, passim también.
}

Rlit, LXVI, 131 (2004), 215-220 
esto da idea de su predicamento) Federico García Lorca, José Bergamín, José María de Cossío, Ramón J. Sender, Pablo Neruda, Rafael Alberti, Manuel Altolaguirre, Luis Cernuda y Pedro Salinas. Se ha dado por supuesta su militancia en el Partido Comunista, dato más que verosímil si se tiene en cuenta que, movilizado como voluntario en el Ejército de la República —en el $5^{\circ}$ Regimiento de Milicias ${ }^{3}$-, desde el 18 de noviembre fue agregado cultural del comisario político Pablo de la Torriente en el batallón de El Campesino.

También se ha asegurado que la personalidad de Miguel Hernández no le hizo propicio para empuñar las armas, de suerte que su acción se habría limitado a la propaganda ${ }^{4}$. El texto de la sentencia de 1940 es sin embargo explícito cuando afirma que intervino «entre otros hechos en la acción contra el Santuario de Santa María de la Cabeza» ${ }^{5}$; aunque es verdad que el resto de los cargos pecó de genérico o se redujo al campo propagandístico.

El hecho es que, al acabar la Guerra, Miguel Hernández se refugió en Portugal, cuyas autoridades lo remitieron sin embargo a España, preso, el 7 de mayo de 1939, y ello por la sola razón de que les pareció persona sospechosa por vender un traje y el reloj que llevaba en la muñeca. Sometido a un proceso sumarísimo de urgencia, se le acusó de «ideales antifascistas y revolucionarios», que él reconoció ${ }^{6}$. Fue puesto en libertad, con todo, el 17 de septiembre 7 ... para volver a ser detenido, ya en Orihuela, el 29 del mismo mes y año. Esta vez, acabaría el 18 de enero de 1940 ante un consejo de guerra, que lo condenó a la pena capital. Fue sometido, por lo tanto, a dos procesos distintos.

Desde el principio de su calvario judicial, Miguel Hernández pidió a los amigos, las más de las veces directamente, por carta, o por medio de su esposa, que intervinieran en su favor ${ }^{8}$. Los amigos: ¿qué amigos? Sabemos de la intervención de bastantes personas. Concretamente, intervinieron José María de Cossío — con quien había trabado amistad en Madrid en 1934—, Pablo Neruda — por medio del embajador de Chile—, Luis Almar-

${ }^{3}$ Según Miguel Gutiérrez Carbonell, Proceso y expediente contra Miguel Hernández. (Ensayo jurídico sobre el derecho represor franquista 1936-45), Alicante, Compás, 1992, pp. 22 y 61, y la propuesta de conmutación de la pena, 18 de marzo de 1943, Archivo Militar de Guadalajara, Comisión Provincial de Examen de Penas, exp. 10.768.

${ }^{4}$ Así se desprende del informe de la alcaldía de Orihuela que cita SÁNCHEZ VIDAL, op. cit., 284.

${ }_{5}$ Cit. Gutiérrez Carbonell, op. cit., y propuesta de conmutación de la pena, 18 de marzo de 1943, Archivo Militar de Guadalajara, loc. cit.

${ }^{6}$ Cit. SÁNCHEZ VIDAL, op. cit., 284.

${ }^{7}$ Cfr. SÁNCHEZ VIDAL, op. cit., 319. Ferris, op. cit., 426, dice que el 15 de septiembre.

${ }^{8} \mathrm{Su}$ visión de todo el proceso, en Josefina MANRESA, Recuerdos de la viuda de Miguel Hernández, Madrid, Ediciones de la Torre, 1981. 
cha (canónigo de la catedral de Orihuela a quien le ligaba una larga amistad, desde los días en que Almarcha, veintrés años mayor que el poeta, le había introducido en la lectura de los clásicos, con criterio amplio, desde fray Luis y Calderón a Verlaine y Gabriel Miró, y había dado cabida a los primeros versos que publicó, en 1930, en El pueblo de Orihuela, órgano de los Sindicatos Católicos auspiciado por el canónigo ${ }^{9}$ ), el oriolano Juan Bellod Salmerón, el también oriolano Tomás López Galindo, José Martínez Arenas, fray Justo Pérez de Urbel, Rafael Sánchez Mazas, José Ibáñez Martín, Vicente Aleixandre, los Álvarez Quintero, Víctor de la Serna, quizás el actor Enrique Borrás, José María Alfaro, el cardenal Braudillart ${ }^{10} \ldots$ y aun podemos añadir, por lo que se verá, a Dionisio Ridruejo.

Otra cosa es saber cuándo y cómo intervinieron en su favor. Ante el primer juicio, el poeta acudió a José María de Cossío, a Neruda, a Almarcha, a Bellod y a López Galindo y, en efecto, fue declarado en libertad por falta de pruebas suficientemente consistentes, pese a que los cargos como propagandista de izquierdas, incluso marxista - habían sido terminantes ${ }^{11}$. De facto, bastó una nueva denuncia - de un oficial del Juzgado Municipal de Orihuela que lo vio pasar por la calle - para que fuera nuevamente encarcelado y procesado. En este segundo juicio fue decisivo otra vez Cossío, que consiguió que varias personas de nota, en el campo de la cultura, firmaran un escrito a favor del poeta y que visitó al ministro del Ejército - José Enrique Varela- acompañado de José María Alfaro y Rafael Sánchez Mazas, que era también ministro, sin cartera, en aquellos momentos ${ }^{12}$.

Cossío fue, sin duda, el que hizo los esfuerzos mayores. Pero no se puede decir que fuera el único, ni que los empeños de los demás fueran ineficaces. Entre otras, no cabe echar en saco roto la eficacia de la gestión de Dionisio Ridruejo - director general de Propaganda en aquella sazón-, ante el propio Rafael Sánchez Mazas y José Ibáñez Martín, ministro de Educa-

${ }^{9}$ Cfr. SÁNCHEZ VIDAL, op. cit., 22; Ferris: op. cit., 22; Juan GUERRERO ZAMORA, Proceso a Miguel Hernández: El sumario 21.001, Madrid, Editorial Dossat, 1990, pp. 181-182. Algunos autores hablan de Almarcha como obispo de León, cargo para el que no fue preconizado, sin embargo, sino en 1944, cuando el poeta llevaba varios años muerto. El dato de la preconización, en Diccionario de historia eclesiástica de España, dirigido por Quintín Aldea Vaquero, Tomás Marín Martínez y José Vives Gatell, Madrid, Consejo Superior de Investigaciones Científicas, 1972, t. II, voz «León».

${ }^{10}$ Vid. la distinta valoración de esta intervención ante Franco, en María Teresa LEón, Memoria de la melancolía, Barcelona, Editorial Bruguera, 1979, p. 336, y FERRIS, op. cit., 416.

11 Vid. SÁNCHEZ VIDAL, op. cit., 284. Sobre la posibilidad de que fuera liberado por error, ibidem, 287.

${ }^{12}$ Cfr. FERRIS, op. cit., 445, y SÁNCHEZ VIDAL, op. cit., 296 y 319. El general Asensio no fue ministro del Ejército hasta 1942. Lo decimos por el equívoco de nombres que hay ibidem, 296. 
ción Nacional. Publicamos la carta, sin fecha, que dirigió Ridruejo a este último, y la respuesta del ministro, de donde se deduce que ellos mismos - aparte de lo que hicieran con José María Cossío- hablaron personalmente con Franco, además de hacerlo con el general Varela ${ }^{13}$ :

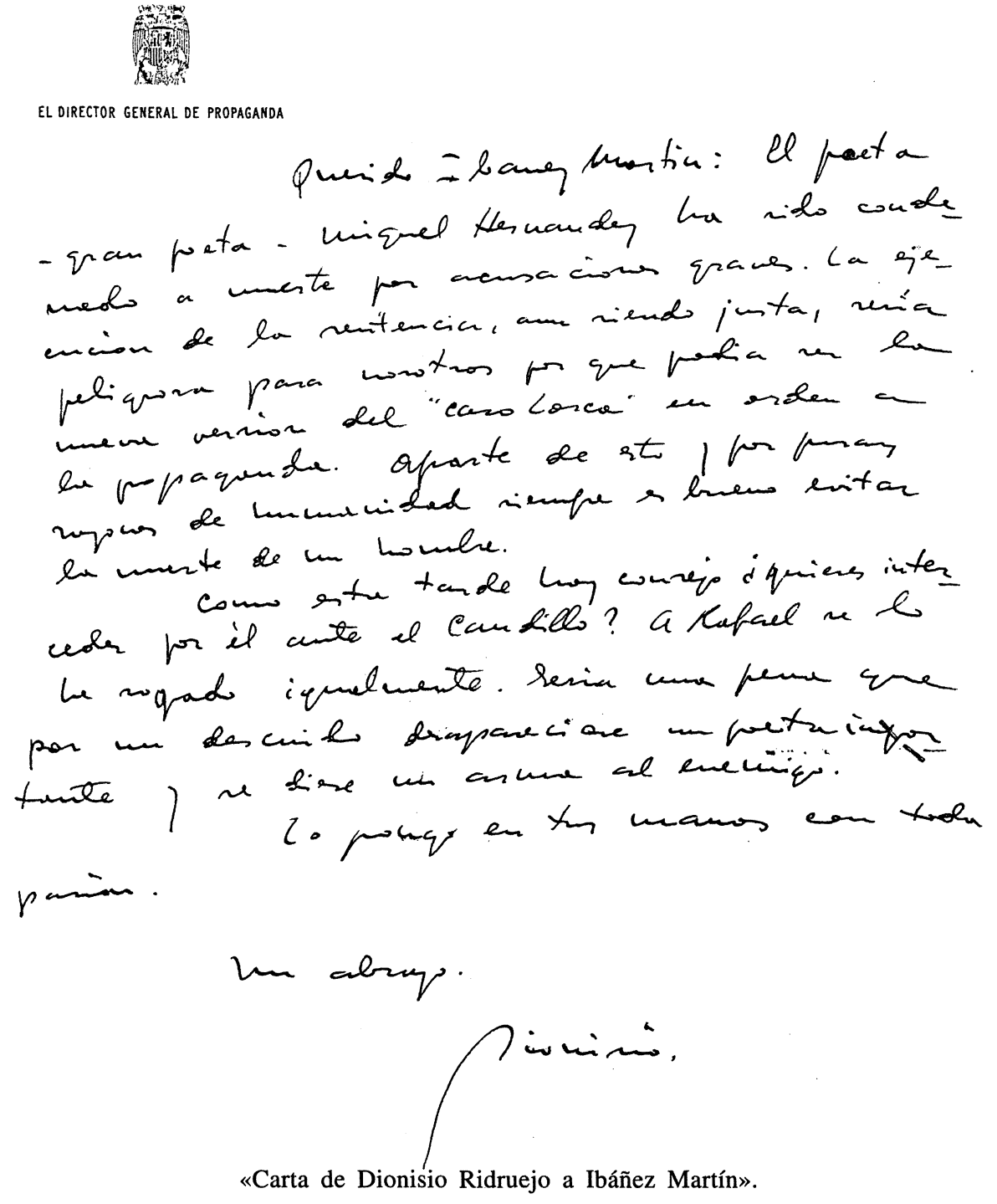

${ }^{13}$ Y que, con la respuesta de Ibáñez Martín, que transcribimos a continuación, se conserva en el Archivo Ibáñez Martín, núm. 32, 2-Ri, 1939-1940-1941 (copia en papel carbón). 
«[Hay un membrete con el escudo de España y la leyenda:] EL DIRECTOR GENERAL DE PROPAGANDA

»Querido Ibáñez Martín: El poeta — gran poeta- Miguel Hernández ha sido condenado a muerte por acusaciones graves. La ejecución de la sentencia, aun siendo justa, sería peligrosa para nosotros porque podía ser la nueva versión del 'caso Lorca' en orden a la propaganda. Aparte de esto y por puras razones de humanidad siempre es bueno evitar la muerte de un hombre.

»Como esta tarde hay consejo ¿quieres interceder por él ante el Caudillo? A Rafael se lo he rogado igualmente. Sería una pena que por un descuido desapareciese un poeta importante y se diese un arma al enemigo.

»Lo pongo en tus manos con toda pasión.

»Un abrazo,

Dionisio».

La respuesta de Ibáñez Martín es ésta:

«Madrid 7 de enero de 1940

»Ilmo. Sr. Don Dionisio Ridruejo

»Director General de Propaganda

»Ministerio de la Gobernación

»M A D R I D

»Mi querido amigo:

»Rafael y yo recomendamos al Caudillo, el mismo día que me enviaste tu carta, la concesión de indulto a favor de Miguel Hernández Gilbert ${ }^{14}$. Posteriormente he hablado con el Ministro del Ejército encareciéndole la importancia y significación, de este hecho, para nuestra acción exterior.

»Un abrazo,

Firma: José Ibáñez Martín.»

Es probable que, tras las gestiones de que se habla en esta carta, fuera cuando Varela y Sánchez Mazas se entrevistaran con Franco para insistirle en el indulto de nuevo.

La fecha de la carta de Ibáñez Martín plantea un problema. En la de Ridruejo - que no lleva data - se habla de que ha sido ya condenado a muerte y, en la de Ibáñez Martín, de 7 de enero, se hace referencia a que se ha pedido el indulto, siendo así que el consejo de guerra no tuvo lugar hasta el 18 de enero y que, el 30 del mismo mes, el auditor de Guerra del Ejército de Ocupación confirmaba la sentencia a la pena capital, sin más que dejarla en suspenso «hasta tanto se reciba el enterado de S.E. el Jefe del Estado» ${ }^{15}$. El indulto no se le comunicaría hasta el 28 de agosto ${ }^{16}$. La única explicación que encontramos es que Ibáñez Martín equivocara el mes, y la carta sea del 7 de febrero de 1940.

${ }^{14}$ Sic, por Gilabert.

${ }^{15}$ Cit. FERRIS, op. cit., 443.

16 Vid. SÁNCHEZ VIDAL, op. cit., 295. La explicación del retraso, en GUERRERo ZAMORA, op. cit., 164, y FERRIS, op. cit., 446-449. 
Sabido es que estas gestiones sólo sirvieron para alargar un poco la vida del poeta. En diciembre de 1941 empezaría a manifestarse en él un paratifus complicado con tuberculosis. No lo dejaron sólo, en estas circunstancias, los amigos que habían intercedido por él. El doctor Antonio Barbero Carnicero le operó dos veces y llegaron a conseguir que se diera orden de trasladarlo al sanatorio de Porta Coeli, en Valencia. Pero la solución llegó tarde. A las cinco y media de la mañana, el 28 de marzo de 1942, a los treinta y dos años, fallecía una de las figuras más notables de la poesía española contemporánea.

\title{
RESUMEN
}

La intervención de Ridruejo e Ibáñez Martín en la vida del poeta Miguel Hernández, por Justo Formentín Ibáñez y José Andrés-Gallego.

Se aporta nueva documentación, procedente del archivo Ibáñez Martín, sobre las gestiones que se hicieron para que Franco indultara al poeta Miguel Hernández en 1940.

Palabras clave: Historia de la Literatura, política, poesía, Miguel Hernández.

\begin{abstract}
With documents of Ibañez Martin archives, the authors explain several political negotiations in order to obtain Franco's amnesty for the poet Miguel Hernández in 1940.
\end{abstract}

Key words: Literature history, politics, poetry, Miguel Hernandez. 